\title{
Exploring the dimensions of doctor-patient relationship in clinical practice in hospital settings
}

\author{
Saurabh RamBiharilal Shrivastava*, Prateek Saurabh Shrivastava, Jegadeesh Ramasamy
}

\section{Abstract}

The Doctor-Patient Relationship (DPR) is a complex concept in the medical sociology in which patients voluntarily approach a doctor and thus become a part of a contract in which they tends to abide with the doctor's guidance. Globally, the DPR has changed drastically over the years owing to the commercialization and privatization of the health sector. Furthermore, the dynamics of the DPR has shown a significant change because of the formulation of consumer protection acts; clauses for professional misconduct and criminal negligence; establishment of patient forums and organizations; massive expansion of the mass media sector leading to increase in health awareness among people; and changes in the status of the doctors. Realizing the importance of DPR in the final outcome and quality of life of the patient, multiple measures have been suggested to make a correct diagnosis and enhance healing. To conclude, good DPR is the crucial determinant for a better clinical outcome and satisfaction with the patients, irrespective of the socio-cultural determinants.

Keywords: Doctor, Doctor-Patient Relationship (DPR), Communication, Hospital

Copyright: @ 2014 by Kerman University of Medical Sciences

Citation: Shrivastava SR, Shrivastava PS, Ramasamy J. Exploring the dimensions of doctor-patient relationship in clinical practice in hospital settings. Int J Health Policy Manag 2014; 2: 159-160. doi: 10.15171/ijhpm.2014.40
Article History:

Received: 6 March 2014

Accepted: 24 April 2014

ePublished: 25 April 2014

\section{Background}

The Doctor-Patient Relationship (DPR) is a complex concept in the medical sociology in which patients voluntarily approach a doctor and thus become a part of a contract in which they tend to abide with the doctor's guidance $(1,2)$. It has been proposed that an ideal DPR has six components, namely voluntary choice, doctor's competence, good communication, empathy by the doctors, continuity, and no conflict of interest (3). In fact, a poor DPR has been proved to be a major obstacle for both doctors and patients, and has eventually affected the quality of healthcare and ability of the patients to cope with their illness. Owing to poor DPR, patients does not show compliance with doctor advice completely; opt for doctor-shopping by changing their doctor repeatedly; remain anxious; may choose quacks or other non-scientific forms of treatment; significant increase in direct and indirect medical expenses. Because of recurrent change in line of treatment as per the advice of different doctors and non-completion of the entire course of drugs, there is a definite scope for the emergence of antimicrobial resistance, which further compounds the medical cost and anxiety, and finally may develop serious forms of disease or complications (4-6). From the doctors' perspective, they may ask for unnecessary investigations or may give over-prescriptions, just to be safe. There is also observed a remarkable decline in human touch or empathy; and a significant rise in unhealthy competition among doctors $(3,7)$.

\section{Changes in the Doctor-Patient Relationship}

The DPR has changed dramatically over the years owing to the commercialization, quality of healthcare services offered in government set-up, sense of community ownership among members of the society, poor sensitization of health workers regarding important local issues, and privatization of the health sector, especially in developing countries (8). However, it has been recommended that irrespective of the continuing reforms in the health services, the patient should always remain the principal focus in the medical care arena (9). Considering the technological superiority and skilled nature of their job, the doctor tends to exercise an authoritative role, which may lead to conflicts if the patient is not willing to accept the same (1). It has been revealed that even doctors and patients that are from the same socio-cultural milieu have variable views pertaining to ill-health (6). Furthermore, the dynamics of the DPR has shown a significant change because of the formulation of consumer protection acts; clauses for professional misconduct and criminal negligence; establishment of patient forums and organizations; expansion of the mass media sector leading to increase in health awareness among people; and changes in the status of the doctors $(10,11)$. In addition, factors like sociocultural determinants (6), poor communication skills of the doctors (12-14), use of medical terms by the clinicians (15), doctors not listening to the complaints of patients $(16,17)$, and a mismatch between the doctors' objectives and patients expectations for the doctor (18), have together created a wide gap in the DPR. All these factors have caused a massive impact on the trust level and the bonding pattern between the clinician and their patients $(6,8,19)$.

Doctor-Patient Relationship: Scope \& recent developments The nature of the DPR has been studied in different clinical and socially sensitive conditions like breast cancer (20); people living with HIV/AIDS (21); and patients with chronic hepatitis-B virus infections (18); to gain an insight into the patient's expectations from the clinicians during the course of their treatment. Even now, especially for chronic lifestyle related disorders, most of the patients still prefer a long-term relationship with their treating physician, as the doctor is well aware of the entire history and reports and the patient being

${ }^{*}$ Department of Community Medicine, Shri Sathya Sai Medical College \& Research Institute, Kancheepuram, India 
acclimatized to the familiar surroundings $(22,23)$. A range of new initiatives has been proposed across the world to improve the DPR, such as use of placebos (24); the emergence of telehealth video consultations, especially for patients with chronic diseases, which requires significant amount of self-care at home (25-27); adoption of psychological models (2); and indirect measures like involving physicians in fund raising initiatives (28). In addition, it has been recommended that the DPR must be widened to a new type of relationship, in which several doctors are treating the same patient as a team (29).

Suggested measures to improve the Doctor-Patient Relationship

Realizing the importance of DPR in the final outcome and quality of life of the patient, multiple measures such as training sessions on communication skills for the doctors (12), sensitizing clinicians to respond to patients emotional cues, encouraging doctors to communicate without/with minimal use of medical terminologies (15), facilitating feedback from the patients after consultation, accelerating the empowerment of the patients (30), teaching DPR skills during undergraduate medical curriculum $(31,32)$, reverting back to the traditional culture to negate the socio-cultural determinants (8), promoting listening by the doctors $(16,17)$, involving family members $(20,21)$, and enabling adoption of newer approach $(2,27)$ have been proposed to make a correct diagnosis, enhance healing, and boost the DPR. In closing, good DPR is the crucial factor to ensure a better clinical outcome and satisfaction with the patients, irrespective of the socio-cultural determinants.

\section{Ethical issues}

Not applicable

\section{Competing interests}

The authors declare that they have no competing interests.

\section{Authors' contributions}

SS prepared the proposal and drafted the manuscript. PS performed review of literature and revised the manuscript critically for intellectual content. JR supervised the research process and provided overall guidance in the writing of the manuscript.

\section{References}

1. Park K. Medicine and social sciences. In: Park K, editor. Textbook of Preventive and Social Medicine. 20th ed. Jabalpur: Banarsidas Bhanot; 2009. p. 604-5.

2. Lejoyeux M. The doctor-patient relationship: new psychological models. Bull Acad Natl Med 2011; 195: 1477-88.

3. Emanuel EJ, Dubler NN. Preserving the physician-patient relationship in the era of managed care. JAMA 1995; 273 : 323-9. doi: 10.1001/jama.1995.03520280069043

4. Institute of Medicine. Crossing the quality chasm: a new health system for the 21st century. Washington, DC: National Academy Press; 2001. doi: 10.1056/NEJM200108303450917

5. Mendoza MD, Smith SG, Eder MM, Hickner J. The seventh element of quality: the doctor-patient relationship. Fam Med 2011; 43: 83-9.

6. Banerjee A, Sanyal D. Dynamics of doctor-patient relationship: A cross-sectional study on concordance, trust, and patient enablement. J Family Community Med 2012; 19: 12-9. doi: 10.4103/2230-8229.94006

7. Werther JR. Focus on doctor-patient relationship the secret to practice success. Tenn Med 2010; 103: 9.

8. Hou X, Xiao L. An analysis of the changing doctor-patient relationship in China. J Int Bioethique 2012; 23: 83-9. doi: 10.3917/ jib.232.0083
9. Dworzanski W, Dworzanska A, Burdan F. The essence of doctorpatient relationship in creating image of a medical institution. Pol Merkur Lekarski 2012; 32: 38-40.

10. Siebzehner MI, Balik C, Matalon A. Doctor-patient relationship in the context of a changing society. Harefuah 2008; 147: 1010-5.

11. Oyer DJ. Playing politics with the doctor-patient relationship. $N$ Engl J Med 2012; 366: 2326-7. doi: 10.1056/NEJMc1205009

12. Finset A. "I am worried, Doctor!" Emotions in the doctor-patient relationship. Patient Educ Couns 2012; 88: 359-63. doi: 10.1016/j. pec.2012.06.022

13. Weber AS, Verjee MA, Musson D, Iqbal NA, Mosleh TM, Zainel AA, et al. Patient opinion of the doctor-patient relationship in a public hospital in Qatar. Saudi Med J 2011; 32: 293-9.

14. Williams S, Weinman J, Dale J. Doctor-patient communication and patient satisfaction: a review. Fam Pract 1998; 15: 480-92. doi: 10.1093/fampra/15.5.480

15. Terpstra OT. On doctor-patient relationship and feedback interventions. Perspect Med Educ 2012; 1: 159-61. doi: 10.1007/ s40037-012-0030-3

16. Snyder U. The doctor-patient relationship II: not listening. Medscape J Med 2008; 10: 294.

17. Jagosh J, Boudreau DJ, Steinert $\mathrm{Y}$, Macdonald ME, Ingram L. The importance of physician listening from the patients' perspective: enhancing diagnosis, healing, and the doctor-patient relationship. Patient Educ Couns 2011; 85: 369-74. doi: 10.1016/j. pec.2011.01.028

18. Pourette D. Chronic hepatitis B and HIV care: the key-role of the doctor-patient relationship. Sante Publique 2013; 25: 561-70.

19. Skirbekk H, Middelthon AL, Hjortdahl P, Finset A. Mandates of trust in the doctor-patient relationship. Qual Health Res 2011; 21: 118290. doi: $10.1177 / 1049732311405685$

20. Kuzari D, Biderman A, Cwikel J. Attitudes of women with breast cancer regarding the doctor-patient relationship. Eur $J$ Cancer Care (Engl) 2013; 22: 589-96. doi: 10.1111/ecc.12063

21. Guenter D, Gillett J, Cain R, Pawluch D, Travers R. What do people living with HIVIAIDS expect from their physicians? Professional expertise and the doctor-patient relationship. J Int Assoc Physicians AIDS Care (Chic) 2010; 9: 341-5. doi: 10.1177/1545109710370486

22. Schers H, Webster S, van den Hoogen H, Avery A, Grol R, van den Bosch W. Continuity of care in general practice: a survey of patients' views. Br J Gen Pract 2002; 52: 459-62.

23. Frederiksen HB, Kragstrup J, Dehlholm-Lambertsen B. Attachment in the doctor-patient relationship in general practice: a qualitative study. Scand J Prim Health Care 2010; 28: 185-90. doi: 10.3109/02813432.2010.505447

24. Benedetti F. Placebo and the new physiology of the doctorpatient relationship. Physiol Rev 2013; 93: 1207-46. doi: 10.1152/ physrev.00043.2012

25. Taylor HJ, Bond CS. What e-patients want from the doctor-patient relationship: content analysis of posts on discussion boards. J Med Internet Res 2012; 14: e155. doi: 10.2196/jmir.2068

26. Sabesan S, Allen D, Caldwell P, Loh PK, Mozer R, Komesaroff PA, et al. Practical aspects of telehealth: doctor-patient relationship and communication. Intern Med J 2014; 44: 101-3. doi: 10.1111/ imj. 12323

27. Lacey C, Huria T, Beckert L, Gilles M, Pitama S. The Hui Process: a framework to enhance the doctor-patient relationship with Maori. N Z Med J 2011; 124: 72-8.

28. Prokopetz JJ, Lehmann LS. Physicians as fundraisers: medical philanthropy and the doctor-patient relationship. PLoS Med 2014; 11: e1001600. doi: 10.1371/journal.pmed.1001600

29. Engestrom Y. From doctor-patient relationship to a collaborative one. Duodecim 2013; 129: 651-5.

30. Chana P. Patient empowerment: a new dimension in doctor-patient relationship. Rev Med Chil 2012; 140: 404-5.

31. Egnew TR, Wilson HJ. Faculty and medical students' perceptions of teaching and learning about the doctor-patient relationship. Patient Educ Couns 2010; 79: 199-206. doi: 10.1016/j.pec.2009.08.012

32. Sommer J, Rieder A, Haller DM. Learning about family medicine and the doctor-patient relationship: student views. Rev Med Suisse 2011; 7: 1100-5. 